
\title{
The Effect Of Nostalgia On Service Failure
}

\author{
Jin A Jeon, Sogang University, South Korea
}

Ja-Yeon Kim, Sogang University, South Korea

\begin{abstract}
Nostalgia induced by savoring precious past experience helps a person feel loved and protected and may help them cope with loneliness. Generally, these positive, prosocial functions, which nostalgia provides, are derived from the content of the memories. However, recent research shows that the process of recalling nostalgic memories could have an important, but different impact on consumers' behavior.

When people face nostalgia through the recollection of positive experience and become aware of its non-repeatability, they seek to enjoy and prolong the experience. Due to the motivation to savor nostalgic experiences, people are likely to be more tolerant of waiting. To this extent, the inclination to reminisce about past experiences motivates people to be more accepting of, thus less dissatisfied with service failure.

Unlike other research focusing on social functions of nostalgia, we examine the effect of nostalgia to a particular service failure: delayed shipping. Nowadays, on-line retailers that use a delivery service is commonplace. Therefore, we believe our research will give critical implications about the effects of nostalgia on service failure. We theorize that nostalgia could have a positive effect on consumer patience, especially for delayed shipping, and the distance to a nostalgic memory affects consumer patience and dissatisfaction. Two studies have confirmed these effects.
\end{abstract}

Keywords: Nostalgia; Consumer Patience; Service Failure

\section{INTRODUCTION}

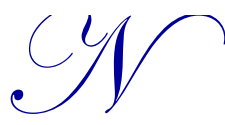

ostalgia refers to a sentimental longing for the past (Sedikides, Wildschut, \& Baden 2004; Zauberman, Ratner, \& Kim 2009). There are so many companies that exploit nostalgic features as marketing campaigns that they are visible nearly everywhere. As Batcho (2007) and Sedikides et al. (2004) have stated, nostalgia is a mixed emotion that includes both joy and sadness. Usually, nostalgic memories are comprised of loving, happy, and precious facets (Davis 1979; Holak \& Havlena 1998; Wildschut, Sedikides, Arndt \& Routledge, 2006). However, once people realize that they are unable to re-experience nostalgia-evoking moments and the wholesome elements of said experiences are forever lost, sadness could become part of nostalgia (Hertz 1990; Johnson-Laird, \& Oatley 1989; Peters 1985).

Prior research shows that nostalgia makes people feel loved and protected, (Juhl, Routledge, Arndt, Sedikides \& Wildschut, 2010) allowing them to better cope with loneliness (Wildschut et al. 2006; Zhou, Sedikides, Wildschut \& Gao, 2008). These positive functions that nostalgia induces are generally led by the content of the memories. However, Huang, Huang, Wyer (2016) showed that the process of recollecting nostalgic memories itself could play an important role. When people sense nostalgia by recalling an experience that they are unable to have again, they strive to enjoy and prolong the experience. This inclination to savor nostalgic experiences compels people to be more tolerant of waiting.

Most research focuses on consumer behavior or attitude. However, we expand the subject to adopt the effects of nostalgia on service failure, particularly on delayed shipping. We predicted that savoring the past causes people to not only endure waiting, but also tolerate service failure and be less dissatisfied with it. In modern times, it is very common for consumers to purchase goods through on-line retailers that deliver the products via shipping service. Therefore, this research could provide important theoretical and managerial implications related to the effect of nostalgia on service failure. 
In the following sections, we summarize literature review about nostalgia, consumer patience, and rosy view from previous research and research hypotheses. Then, we exhibit two studies that examine the hypotheses. Lastly, the research conclusion discusses our findings and implications.

\section{THEORETICAL BACKGROUND}

\section{Nostalgia}

Nostalgia, a sentimental longing for the past, is very widely used for various marketing promotions by both companies and charity organizations. For example, in 2015, Coca-Cola relaunched Surge, which had been sold in the 1990's. Also, PepsiCo reproduced Mountain Dew Pitch Black as a limited edition and Pepsi Crystal in 2009. These nostalgic promotions prompted consumers to reminisce.

Hofer, who introduced the term 'nostalgia', thought of it as a medical illness. Davis (1979, p. 18) defined nostalgia as "a positively toned evocation of a lived past" and Holbrook and Schindler (1991) proposed that nostalgia is "a preference (general liking, positive attitude, or favorable affect) toward objects (people, places, or things) that were more common (popular, fashionable, or widely circulated) when one was younger (in early adulthood, in adolescence, in childhood, or even before birth)" (p. 330).

Nostalgia is a mixed emotion of both joy and sadness. Most nostalgic events consist of loving, happy, precious experiences, but once people realize the precious moments can never reoccur and the desirable facets have vanished, sadness may become part of nostalgia (Hertz 1990; Johnson-Laird, \& Oatley 1989; Peters 1985). People who sense nostalgia feel that they are protected and loved (Juhl et al. 2010), and that they are better equipped to manage loneliness (Wildschut et al.2006; Zhou et al. 2008).

Usually, these positive effects of nostalgia are based on the content of the nostalgic experiences, but Huang et al (2016) showed that not only the content, but also the process of recollecting nostalgic memories could have an effect. When people reminisce about valuable experiences that trigger nostalgia but can never occur again, they strive to enjoy and prolong the experience. This savoring of nostalgic experiences makes people more tolerant of waiting.

When people savor a past experience, they try to make time to enjoy the memory. The non-repeatability of precious past experience can intensify the motivation to reminisce (Areni \& Black 2015; Kurtz 2008; Rozin, Kabnick, Pete, Fischler \& Shields, 2003). If they notice the fleeting nature of the experience, they spend more time to savor it (Bryant $\&$ Veroff 2007). Most research on savoring showed that prolonging the enjoyment of the past experience is the most influential part of savoring (Areni \& Black 2015; Bryant 2003; Bryant \& Veroff, 2007; Fisher, Rolls, \& Birch 2003).

Therefore, people who undergo a nostalgic experience take time to reminisce about valuable memories. This longing to savor permits people to prolong the pleasure of the positive events, and leads them to become more patient with the reminiscing process. To this extent, people who look back on nostalgic events are more likely to show patience with unrelated situations. Prior research shows that people who feel nostalgia had more patience. For example, people who felt nostalgia chose standard delivery more than express, and estimated a shorter time of waiting (Huang et al. 2016).

\section{Consumer Patience}

Service failure refers to problems that occur when consumers experience the service. However, much companies, providers, or consumers try to avoid the failure, it is near impossible to eradicate. For tangible products, when problems arise, companies resort to refunding or exchanging the item. However, when it comes to service failure, the problem is not so simple and creates the biggest threat to consumer satisfaction. These service failures are often caused by service delays, a service person's attitudes, error in billing, or other consumers' reactions (Bitner, Booms \& Tetreault, 1990).

Waiting, one of the most common service failures, exists in every moment of life. However, sometimes consumers do not notice waiting. For example, people wait for dishes in a restaurant or delivery from on-line retailers. Generally, 
people do not want to wait (Grewal, Baker, Levy \& Voss, 2003), as waiting time has a negative relation with satisfaction to the providers (Hui \& Tse 1996; Taylor, 1995; Taylor \& Claxton 1994).

Numerous studies deal with consumer patience in the way of subjective feelings (Chen, $\mathrm{Ng}, \&$ Rao 2005; House, DeVoe, \& Zhong 2013; Rudd, Vohs, \& Aaker 2012), estimates of waiting time (Gorn, Chattopadhyay, Sengupta \& Tripathi, 2004; House et al. 2013), assortment size choice (Bartels \& Urminsky 2011; Hoch \& Loewenstein 1991; Kim \& Zauberman 2013; Kim, Zauberman, \& Bettman 2012; Li 2008; Van den Bergh, Dewitte, \& Warlop 2008), delivery period choice (Chen et al. 2005; May \& Monga 2014), etc. Situational factors could impact consumer patience by influencing consumers' time perception. Also, personal differences, such as culture, have an impact (Chen et al. 2005). Finally, nostalgia has a positive impact on consumer patience by leading people to savor the past (Huang et al. 2016).

\section{Rosy View in Retrospection}

Recalling past events implies that people think their experiences are distant from the present. Researchers have suggested that such a nature of retrospection influences people's perspective of the past (Wirtz, Kruger, Scollon \& Diener 2003; Mitchell, Thompson, Peterson \& Cronk 1997). Evidence from these studies have shown that people have a "rosy view" of their past (Taylor 1991; Mitchell et al. 1997; Pennebaker 1997; Walker, Vogl, \& Thompson 1997; Raghubir \& Latimer 2013). Mitchel et al. (1997) referred to a rosy view in people's anticipation and retrospection associated with their personal events. They recognized that people recollected personal events more positively than when they actually experienced them.

Substantial works have tried to account for this tendency. According to Taylor (1991), people will have strong reactions to negative experiences at the time they were experienced. However, he suggested that the impact of those negative experiences fades out as time passes. Pennebaker's (1997) research also presented similar results. People who wrote about a traumatic experience felt reduced negative feelings at a later time when recalling the experience. Walker et al. (1997) examined people's recall of daily pleasant and unpleasant experiences and found asymmetry in their fading process. They identified that negative affect involved in unpleasant experiences fades faster than positive affect involved in pleasant experiences. They named the asymmetry "Fading Affect Bias".

\section{Hypothesis}

Huang et al.'s (2016) research shows that people who reminisce about nostalgic experience have more patience. In their experiments, people who felt nostalgia chose standard delivery more than express, and estimated a shorter waiting time. They explained that savoring nostalgic experiences makes people more tolerant of waiting.

Our current study, having a similar perspective, suggests that the effects of nostalgia on consumer patience can also be applied to unrelated service failure situations. Because nostalgia is known to enhance consumer patience, we expect consumers who feel nostalgia are more generous about service failures, especially delayed shipping situations. Namely, we predict:

H1: Nostalgia will have a positive impact on consumer patience for delayed shipping.

Meanwhile, most research has shown that people have a "rosy view" of their past (Taylor 1991; Mitchell et al. 1997; Pennebaker 1997; Walker et al.1997). Evidence from those studies has suggested negative affect associated with past experiences fades faster than positive affect. Therefore, we predict that people are more likely to have detailed neutral or negative memories about their relatively recent nostalgic events (vs. remote nostalgic events). People consider experiences that happened long ago more positively. According to this idea, we assumed that it is more impactful to evoke more distant nostalgic feelings (vs. more recent nostalgia) in order to improve consumer patience and reduce dissatisfaction. More formally:

H2: Time distance to nostalgic experience will impact consumer patience and dissatisfaction. 
H2a: A remote nostalgic memory (vs. a relatively recent nostalgic memory) will have a positive effect on consumer patience.

H2b: A remote nostalgic memory (vs. a relatively recent nostalgic memory) will mitigate consumer dissatisfaction.

\section{STUDY 1}

Study 1 tested the hypothesis that nostalgia will have a positive effect on consumer patience for delayed delivery, which is an example of service failure. If nostalgia causes consumer patience, consumers in situations of delayed shipping will be more generous. Our assumption was tested by checking whether or not there is a difference in willingness to wait (expressed in days) between consumers feeling nostalgia and consumers who do not feel nostalgia.

\section{Method}

Participants and Design. A total of 48 undergraduates in Seoul, Korea participated in Study 1 in exchange for a light snack. Participants were randomly assigned to one of the two conditions (nostalgia vs. control).

Procedure. Participants in Study 1 were asked to write more than seven lines about a topic we presented. Participants in control group were told that the researchers' purpose of this study was to collect their daily experiences and they were asked to write down personal, ordinary events in their lives. Participants in the nostalgia group were asked to recall and write down "a past event in your life that makes you feel nostalgic whenever you think about it" (Huang et al. 2016; Routledge, Arndt, Sedikides \& Wildschut, 2008; Routledge et al. 2011). Next, we presented the participants with two nostalgic items to check our manipulation. The two manipulation check items were "Right now, I am feeling quite nostalgic" and "Right now, I am having nostalgic feelings" on a scale ranging from 1 (strongly disagree) to 9 (strongly agree) as Huang et al. (2016) did.

After the priming task, participants were asked to imagine that they purchased clothes from an on-line retailer that typically delivers in 2-3 days. While waiting for the clothes they ordered, participants were notified that an error occurred while shipping and the product delivery would be delayed. Participants were asked to indicate in days how long they would be willing to wait.

\section{Results and Discussion}

Manipulation Checks. Participants who were asked to recall and write about nostalgic events $(M=6.67, \mathrm{SD}=1.23)$ felt more nostalgic than those who were asked to write about ordinary events $(M=2.90, \mathrm{SD}=1.7, t(48)=8.80, p<$ $.001)$. These results indicate that the priming was successful.

Consumer Patience for the Delayed Shipping. Hypothesis 1 predicted that nostalgia would enhance consumer patience for delayed shipping. Participants in the nostalgia group were willing to wait more than those in the control group when a delay in shipping happened. Participants in the nostalgia condition were willing to wait for an average of 6.04 days $(M=6.04)$, indicating enhanced consumer patience, while participants in the control condition were willing to wait for an average of 4.67 days $(M=4.67, t(48)=1.896, p=.064)$.

Table 1. Effects of Nostalgia Priming: Study 1

\begin{tabular}{l|c|c}
\hline & Nostalgia group & Control group \\
\hline Nostalgic feelings & 6.67 & 2.90 \\
\hline Willing-to-wait (in days) & 6.04 & 4.67 \\
\hline
\end{tabular}

\section{Discussion}

Previous research identified an effect of nostalgia that can increase consumer patience (Huang et al. 2016). In the current research, we replicated an experiment to find out that the effect of nostalgia can be applied to service failure situations. If nostalgic memories increase consumer patience, consumers will have more patience for service failure, 
especially delayed shipping. As table 1 shows, consumers' patience for delayed shipping was higher when nostalgia was evoked. When consumers feel nostalgia, they are more willing to wait longer. As for consumers with no nostalgic feelings, they aren't willing to wait as long as the nostalgia group. Therefore, Study 1 identified that evoked nostalgia can help to deal with service failure.

\section{STUDY 2}

In study 1, we acknowledged that consumers' evoked nostalgia increases consumer patience. Additionally, we examined whether the distance of time to the nostalgic experiences can influence the extent of consumer patience and dissatisfaction. Consumers tend to recall previous experiences more positively due to a "rosy view" in retrospective evaluations. Therefore, we assumed that it is more helpful to evoke more distant nostalgic feelings to improve consumer patience and lower dissatisfaction. Our prediction was tested by checking whether or not there is a difference in willingness to wait (expressed in days) and consumer dissatisfaction between consumers with more remote nostalgia and consumers who have relatively recent nostalgia.

\section{Method}

Participants and Design

A total of 60 undergraduates in Seoul, Korea participated in Study 2 in exchange for a light snack. Participants were randomly assigned to one of the two conditions (remote nostalgia vs. recent nostalgia).

\section{Procedure}

The procedure of Study 2 follows that of Study 1. Participants in Study 2 were asked to write more than seven lines about the topic we presented. Participants in remote nostalgia were asked to recall and write about "a past event from about 10 years ago that makes you feel nostalgic whenever you think about it." In the recent nostalgia group, we asked the participants to write about "a past event about 3 years ago in your life that makes you feel nostalgic whenever you think about it." Participants then indicated how long ago the event had occurred in years. We also asked participants to respond to two manipulation check items used in Study 1.

Following the same procedure from Study 1, after the priming task, participants were asked to imagine that they purchased clothes from an on-line retailer that typically delivers in 2-3 days. While waiting for the clothes they ordered, participants were notified that an error occurred while shipping and the product delivery would be delayed. Participants were asked to indicate in days how long they would be willing to wait. We also measured the extent to which participants felt dissatisfaction with this situation. This variable was captured with a two-item dissatisfaction index which consisted of "As a whole, you are not satisfied with the delivery service of the on-line retailer" and "You are unhappy about your experience with the delivery service of the on-line retailer" (with reference to Chan, Wan and Sin 2009). All the items were measured with 9 -point scales $(1=$ strongly disagree; $9=$ strongly agree $)$.

\section{Results and Discussion}

\section{Manipulation Checks}

The results show that both the remote nostalgia group and the recent nostalgia group felt nostalgia. Participants' nostalgic feelings in remote nostalgia and recent nostalgia did not differ $(6.88$ vs. $6.71, t(60)=.508, p>.60)$.

\section{Consumer Patience for the Delayed Shipping}

Hypothesis 2 predicted that the effect of nostalgia on consumer patience is moderated by the extent to which time has passed since the nostalgic events occurred. The more distant the nostalgic experiences are, the more positive feelings consumers have. Therefore, remote nostalgia will have a greater positive impact on consumer patience and mitigate consumer dissatisfaction more than recent nostalgia when a service failure occurs (Hypothesis $2 \mathrm{a}$ and $2 \mathrm{~b}$ ). 
The results of Study 2 support our hypotheses. Participants in the remote nostalgia condition were willing to wait longer than those in the recent nostalgia group when a delay in shipping occurred. Participants in the remote nostalgia group were willing to wait for an average of 6.34 days $(M=6.34)$, indicating enhanced consumer patience, while participants in control group were willing to wait for an average of 4.61 days $(M=4.61, t(60)=2.314, p<.05)$. Consumer dissatisfaction is lower in the remote nostalgia group $(M=5.55)$ than it is in the recent nostalgia group $(M$ $=6.52, \mathrm{t}(60)=-2.310, p<.05)$.

Table 2. Effects of Nostalgia Priming: Study 2

\begin{tabular}{l|c|c}
\hline & Remote nostalgia group & Recent nostalgia group \\
\hline Nostalgic feelings & 6.88 & 6.71 \\
\hline Willing-to-wait (in days) & 6.34 & 4.61 \\
\hline Dissatisfaction & 5.55 & 6.52 \\
\hline
\end{tabular}

\section{Discussion}

In study 1, we identified that consumers' evoked nostalgia would be helpful to deal with service failure. We also assume that the effect of nostalgia on consumer patience is moderated by the extent to which time has passed since the nostalgic events occurred. The more distant the nostalgic memory the consumer conjures up, the more favorable the effect on service failure (e.g. delayed shipping). As table 2 shows, consumers' patience for delayed shipping was higher when relatively more distant nostalgia was evoked. When consumers felt relatively more distant nostalgia, they were more willing to wait longer. However, consumers with relatively recent nostalgic feelings were not willing to wait as long as the remote nostalgia group. These results support the idea that consumers with more distant nostalgia will have more positive memories and are more likely to be patient.

The effect of nostalgia can also have an influence on mitigating consumer dissatisfaction through increased patience. When delayed shipping occurred in the scenario, the level of consumer dissatisfaction was lower in the remote nostalgia condition than the recent condition. According to the results, marketers who encounter service failure should evoke nostalgia as old as possible to attenuate consumer dissatisfaction.

\section{CONCLUSION}

Most research on nostalgia focuses on the social functions of nostalgia, such as donation intention and social interaction. However, Huang et al.'s (2016) study highlighted not only the content, but also process of recollecting nostalgic memories. The researchers explained that people in the process of recollection would long to savor the nostalgic experience, leading them to be more patient.

In our research, we would like to identify that the effects of nostalgia on consumer patience could also be applied to service failure situations with a similar perspective. We propose that consumers are more content with service failure due to a rise in patience from recalling nostalgic memories. The results of Study 1 demonstrated that participants were more willing to wait for delayed shipping when nostalgia was evoked.

In addition, we suggested that the effect of nostalgia on consumer patience is moderated by the extent to which time has passed since a nostalgic event transpired. People tend to have a "rosy view" of their past (Taylor 1991; Mitchell et al. 1997; Pennebaker 1997; Walker et al. 1997) because of "Fading Affect Bias", which means negative affect fades faster than positive affect in recollection. We predicted that consumers who feel more distant nostalgia are more likely to savor their past and are more willing to wait longer. We also suggested that this moderating effect can influence mitigating consumer dissatisfaction with increased patience. Particularly, we proposed that consumers who recall distant nostalgic events are less dissatisfied with the service failure. The results of Study 2 indicated that the level of consumer dissatisfaction was lower in the remote nostalgia condition than the recent condition in the delayed shipping scenario.

Overall, Huang et al.'s (2016) study shows that the process of reminiscing nostalgic memories leads people to be more patient. In addition to previous study, the current research identifies that the effect of nostalgia could have an important 
role on decreasing dissatisfaction due to service failure. Also, contrasting with previous literature, we demonstrate that the temporal distance of nostalgic memories could moderate the impact of nostalgia. Shown as Study 2, consumers who recall more distant nostalgia tend to savor their past and have more patience to service failure.

According to the results, it is helpful for marketers to evoke consumers' nostalgia when faced with a service failure situation. Especially, marketers who have to manage a service failure should evoke nostalgia as distant as possible in order to mitigate consumer dissatisfaction. For instance, companies prefer to provide compensation for inconvenience when service failure occurs. In that case, it might be better to offer indemnifications which could evoke more distant nostalgic memories.

There are limitations with this research. We conducted experiments with undergraduate students as participants in controlled environment in order to clarify the causal relationship between nostalgia and consumer patience. However, to generalize the effect of nostalgia, it is necessary to use other samples such as Baby Boomers or Gen X. Also, it might be helpful to increase the sample size for better statistical analysis. Lastly, we suggest that future researches could investigate factors that moderate or mediate the effect of nostalgia like magnitude or vividness of recalling the memories.

\section{AUTHOR BIOGRAPHIES}

Jin A Jeon is a doctoral student at Graduate School of Business, Sogang University. Her research interest is consumer decision making with a special focus on time contraction, nostalgia, and goal pursuit. E-mail: jeongina@sogang.ac.kr

Ja-Yeon Kim is a Ph.D. candidate in Marketing at Graduate School of Business, Sogang University. Her research interest is consumer behavior, especially focusing on gift-giving, cultural difference, and nostalgia. E-mail: jayeon@sogang.ac.kr (Corresponding author).

\section{REFERENCES}

Areni, C. S., \& Black, I. (2015). Consumers' responses to small portions: Signaling increases savoring and satiation. Psychology \& Marketing, 32(5), 532-543.

Bartels, D. M., \& Urminsky, O. (2011). On intertemporal selfishness: How the perceived instability of identity underlies impatient consumption. Journal of Consumer Research, 38(1), 182-198.

Batcho, K. I. (2007). Nostalgia and the emotional tone and content of song lyrics. The American Journal of Psychology, $361-381$.

Bitner, M. J., Booms, B. H., \& Tetreault, M. S. (1990). The service encounter: Diagnosing favorable and unfavorable incidents. The Journal of Marketing, 71-84.

Bryant, F. B. (2003). Savoring Beliefs Inventory (SBI): A scale for measuring beliefs about savoring. Journal of Mental Health, 12(2), 175-196.

Bryant, F. B. \& Veroff J. (2007). Savoring: A new model of positive experience. Mahwah, NJ: Erlbaum.

Chan, H., Wan, L.C. \& Sin L. Y. M. (2009). The contrasting effects of culture on consumer tolerance: Interpersonal face and impersonal fate. Journal of Consumer Research, 36(2), 292-304.

Chen, H., Ng, S., \& Rao, A. R. (2005). Cultural differences in consumer impatience. Journal of Marketing Research, 42(3), 291301.

Davis, F. (1979). Yearning for yesterday: A sociology of nostalgia. New York: The Free Press.

Fisher, J. O., Rolls, B. J., \& Birch, L. L. (2003). Children's bite size and intake of an entree are greater with large portions than with age-appropriate or self-selected portions. American Journal of Clinical Nutrition, 77(5), 1164-1170.

Gorn, G. J., Chattopadhyay, A., Sengupta, J., \& Tripathi, S. (2004). Waiting for the web: How screen color affects time perception. Journal of Marketing Research, 41(2), 215-225.

Grewal, D., Baker, J., Levy, M., \& Voss, G. B. (2003). The effects of wait expectations and store atmosphere evaluations on patronage intentions in service-intensive retail stores. Journal of retailing, 79(4), 259-268.

Hertz, D. G. (1990). Trauma and nostalgia: new aspects on the coping of aging Holocaust survivors. Israel Journal of Psychiatry and Related Sciences, 27(4), 189-198.

Hoch, S. J., \& Loewenstein, G. F. (1991). Time-inconsistent preferences and consumer self-control. Journal of Consumer Research, 17(4), 492-507.

Holak, S. L., \& Havlena, W. J. (1998). Feelings, fantasies, and memories: An examination of the emotional components of nostalgia. Journal of Business Research, 42(3), 217-226.

Holbrook, M. B., \& Schindler, R. M. (1991). Echoes of the dear departed past: Some work in progress on nostalgia. Advances in Consumer Research, 18, 330-333. 
House, J., DeVoe, S. E., \& Zhong, C. B. (2013). Too impatient to smell the roses: Exposure to fast food impedes happiness. Social Psychological and Personality Science, 5(5), 534-541.

Huang, X. I., Huang, Z. T., \& Wyer, R. S. (2016). Slowing down in the good old days: The effect of nostalgia on consumer patience. Journal of Consumer Research, 43(3), 372-387.

Hui, M. K., \& Tse, D. K. (1996). What to tell consumers in waits of different lengths: An integrative model of service evaluation. The Journal of Marketing, 81-90.

Johnson-Laird, P. N., \& Oatley, K. (1989). The language of emotions: An analysis of a semantic field. Cognition and Emotion, $3(2), 81-123$.

Juhl, J., Routledge, C., Arndt, J., Sedikides, C., \& Wildschut, T. (2010). Fighting the future with the past: Nostalgia buffers existential threat. Journal of Research in Personality, 44(3), 309-314.

Kim, B. K., \& Zauberman, G. (2013). Can Victoria's Secret change the future? A subjective time perception account of sexualcue effects on impatience. Journal of Experimental Psychology: General, 142(2), 328-335.

Kim, B. K., Zauberman, G., \& Bettman, J. R. (2012). Space, time, and intertemporal preferences. Journal of Consumer Research, $39(4), 867-880$

Kurtz, J. L. (2008). Looking to the future to appreciate the present: The benefits of perceived temporal scarcity. Psychological Science, 19(12), 1238-1241.

Li, X. (2008). The effects of appetitive stimuli on out-of-domain consumption impatience. Journal of Consumer Research, 34(5), 649-656.

May, F., \& Monga, A. (2014). When time has a will of its own, the powerless don't have the will to wait: Anthropomorphism of time can decrease patience. Journal of Consumer Research, 40(5), 924-942.

Mitchell, T. R., Thompson, L., Peterson, E., \& Cronk, R. (1997). Temporal adjustments in the evaluation of events: The "rosy view". Journal of Experimental Social Psychology, 33(4), 421-448.

Pennebaker, J. W. (1997). Writing about emotional experiences as a therapeutic process. Psychological Science, 8(3), $162-166$.

Peters, R. (1985). Reflections on the origin and aim of nostalgia. Journal of Analytical Psychology, 30(2), 135-148.

Raghubir, P. \& Latimer, R. (2013). Motivated recall and the "rosy view" in retrospective evaluations. Advances in Consumer Research, (41), 388-391.

Routledge, C., Arndt J., Sedikides, C., \& Wildschut, T. (2008). A blast from the past: The terror management function of nostalgia. Journal of Experimental Social Psychology, 44(1), 132-140.

Routledge, C., Arndt, J., Wildschut, T., Sedikides, C., Hart, C. M., Juhl, J., \& Schlotz, W. (2011). The past makes the present meaningful: Nostalgia as an existential resource. Journal of Personality and Social Psychology, 101(3), 638-652.

Rozin, P., Kabnick, K., Pete, E., Fischler, C., \& Shields, C. (2003). The ecology of eating smaller portion sizes in France than in the United States help explain the French paradox. Psychological Science, 14(5), 450-454.

Rudd, M., Vohs, K. D., \& Aaker, J. (2012). Awe expands people's perception of time, alters decision making, and enhances wellbeing. Psychological Science, 23(10), 1130-1136.

Sedikides, C., Wildschut, T., \& Baden, D. (2004). Nostalgia: Conceptual issues and existential functions. (in) The Handbook of Experimental Existential Psychology, Greenberg, J., Koole, SL, and Pyszczynski, TA (eds). New York.200-214.

Taylor, S. E. (1991). Asymmetrical effects of positive and negative events: the mobilization-minimization hypothesis. Psychological Bulletin, 110(1), 67-85.

Taylor, S. (1995). The effects of filled waiting time and service provider control over the delay on evaluations of service. Journal of the Academy of Marketing Science, 23(1), 38-48.

Taylor, S., \& Claxton, J. D. (1994). Delays and the dynamics of service evaluations. Journal of the Academy of Marketing Science, 22(3), 254-264.

Van den Bergh, B., Dewitte, S. \& Warlop, L. (2008). Bikinis instigate generalized impatience in intertemporal choice. Journal of Consumer Research, 35(1), 85-97.

Walker, W. R., Vogl, R. J., \& Thompson, C. P. (1997). Autobiographical memory: Unpleasantness fades faster than pleasantness over time. Applied Cognitive Psychology, 11(5), 399-413.

Wildschut, T., Sedikides, C., Arndt, J., \& Routledge, C. (2006). Nostalgia: content, triggers, functions. Journal of Personality and Social Psychology, 91(5), 975-993.

Wirtz, D., Kruger, J., Scollon, C. N., \& Diener, E. (2003). What to do on spring break? The role of predicted, on-line, and remembered experience in future choice. Psychological Science, 14(5), 520-524.

Zauberman, G., Ratner, R. K., \& Kim, B. K. (2009). Memories as assets: Strategic memory protection in choice over time. Journal of Consumer Research, 35(5), 715-728.

Zhou, X., Sedikides, C., Wildschut, T., \& Gao, D. G. (2008). Counteracting loneliness on the restorative function of nostalgia. Psychological Science, 19(10), 1023-1029. 